Part II starts out with a chapter on artificial insemination with donor semen, outlining the techniques used including those for banking frozen semen, and the ethical, psychological and legal problems. The problems of AID for the treatment of infertility are great enough but Dr Karp also discusses the even greater problems raised by suggestions for its deliberate use in eugenic breeding and also the limitations on what such a practice could achieve. In practical terms there is no undue difficulty about using amniocentesis and abortion as a method of prenatal sex-determination. Many would regard this procedure as justified to prevent the birth of boys with severe X-linked diseases but its use merely to enable a couple to choose the sex of normal children is ethically unacceptable to most people and, in Britain as well as most of the United States, illegal. Pre-conceptional sex-determination on the other hand does not have the same ethical objections but awaits a reliable method for use in man. If such a method comes out of current research then there are, if not ethical, at least social and demographic implications that are discussed.

The remaining chapters deal with more futuristic techniques such as the work of Edwards and others on in vitro fertilization in the treatment of infertility. More controversial are suggestions for the use of a donor egg or a foster mother. Experimental parthenogenesis and cloning of an individual's cells to give rise to new identical individuals are even more futuristic and Dr Karp shows that they are little more than journalistic speculation.

Finally, the possibility of synthetizing DNA or short genes is discussed. It is conceivable that this might one day provide a mechanism for gene correction in patients with certain inherited diseases through the injection of synthetic 'viruses' carrying the missing gene.

This book presents an informative account and a balanced view of the implications of the scientific developments, present and foreseeable, in genetics and reproduction that have been the subject of sensational accounts and speculation elsewhere. It presents the issues in a clear, easily followed manner that should be intelligible to any reasonably well educated layman and as such is a service to the cause of improving the ordinary citizen's understanding of human biology and genetics. As this is a role that most scientists eschew, Dr Karp is to be commended for redressing the balance in this important public debate.

At $\$ 15.00$ even with a glossary, references and index, the price is perhaps a little too high to achieve very large sales.

\section{The House Physician's Handbook}

By C. Allan Birch. 4th edition. Pp. xv 320, illustrated, soft cover. Churchill Livingstone, Edinburgh, 1977. $£ 3.75$.

This remarkable little book has been the houseman's guide for over 20 years and it is great credit to its author that it is now in its fourth edition.

This book follows the pattern of previous editions but new sections have been included on house physicians' hazards, battered babies, techniques of electrocardiography and peritoneal dialysis, although there are details in this latter section with which this reviewer would disagree.

The chapter on The Medical Laboratory has a new author and has been provided by Dr J. Surtees.

This book can be recommended for the wide range of sensible advice it offers to new housemen. It makes valuable suggestions on a wide range of topics from note-taking to getting on with the boss. There are brief notes on all the important procedures and lists of laboratory investigations and how to perform the relevant tests on the ward.

In a book of this type there are bound to be variations in patient management where descriptions are inevitably brief. However, surely a reference to daily weighing should have been made in any section on fluid balance or rena! failure. The diagnosis of Addison's disease rests on the result of a synacthen test rather than a simple cortisol. Physiotherapy should also play a large part in the management of respiratory failure. This section, in the opinion of the reviewer, is the weakest part of the book. Nevertheless, the book has much to recommend it and its popularity is sure to continue.

\section{Intestinal Ischaemia}

By Adrian Marston. Pp. 190, illustrated, hard cover. Edward Arnold, London, 1977. £10.95.

Intestinal ischaemia presents classically as a catastrophic emergency with gangrene of much of the small intestine and with a very high mortality rate. Recent years have brought with them the recognition of lesser degrees of ischaemia, with the description of ischaemic colitis, which particularly affects the left colon, and of the syndrome (probably rarer than the enthusiasts' claim) of 'intestinal angina'. Because of the ever-increasing interest in this topic, the publication of a monograph on intestinal ischaemia by a recognized authority on this subject is to be welcomed. Mr Marston has produced a clearly written and well illustrated account of the subject. He includes the anatomy, physiology and pathology of intestinal blood flow, discusses the clinical and experimental aspects of disturbances of intestinal circulation and their treatment, and does not hesitate to point out where our knowledge ends and speculation takes over. This is a book which will appeal to the whole spectrum of gastroenterologists-surgeons, physicians, radiologists and pathologists -and can be strongly recommended as an authoritative account of an important topic.

\section{Introduction to Research in Medical Sciences}

By A. Cuschieri and P. R. Baker. Pp. 216, illustrated, soft cover. Churchill Livingstone, Edinburgh, 1977. $£ 3.95$.

How do you become a research worker; by reading a book or by apprenticeship to an established investigator? Your conservative, reactionary reviewer was convinced of the second alternative, until faced with this book which demonstrates the diverse areas with which an aspiring Nobel Prize winner should become familiar as he enters his chosen field of investigation. It deals, amongst other things, with the practical problems of information sources, experimental design, statistical analysis, legal requirements, animal models and accommodation, laboratory equipment, principles of some analytical techniques and electronics, and basic techniques in animal and human experimentation. Furthermore, it gives some advice on the most important problem of all, financial support. Useful suggestions for further reading in depth are given in each chapter. No one should imagine that reading this book will produce a research fellow overnight, but this will be invaluable introductory reading for the enthusiastic novice in his first few weeks in a research department.

\section{Metabolism and the Response to Injury}

Edited by A. W. Wilkinson and Sir David Cuthbertson. Pp. 350, illustrated, hard cover. Pitman Medical, Tunbridge Wells, 1977. $£ 10.00$.

Though retrospective research has revealed many writings on the metabolic response to injury before the late $1920 \mathrm{~s}$, all are agreed that Sir David Cuthertson, while working in Glasgow, had the inspiration and the technical skills to document striking changes in energy expenditure and nitrogen balance after skeletal injury. From there he went on to provide much more evidence that profound changes in general body metabolism and substrate utilization flows from trauma. Ever since, his intellectual stature and generous personality 
have dominated the scene; therefore, it is fitting that a commemorative volume should be assembled on his seventyfifth birthday. Even more fitting that he should help edit it and that his associate should be Professor Andrew Wilkinson who, as is now not as well remembered as it might be, was the first to pick up Cuthbertson's initiative shortly after World War II.

As an overview the volume is almost wholly admirable. Each section is dealt with by a world expert. The only omission is a good account of the hormonal changes in and after injury and there is less on electrolyte changes than might have been desirable. However, whether these matters are included turns on the definition of the metabolic response to injury and most of the interest in the last few years has centred on substrate utilization.

This is a book primarily for the interested expert. It lays the basis of therapy but does not discuss it in detail. However, there are interesting sidelights on fever, on hypermetabolism and on much which will be of interest to many outside surgery. No clinical metabolist can afford to be without it.

\section{Nursing Procedures for Skin Diseases}

By Eileen Huckbody. Pp. 135, illustrated, soft cover. Churchill Livingstone, Edinburgh, 1977.

This is an attractive loose-leaf comprehensive book written by the Matron of St John's Hospital for Diseases of the Skin, London, and gives sensible information and practical instruction for nurses who are looking after patients suffering from skin disease. What to do for cardiac arrest is even included. A book for Sister's desk in the Dermatological Out-Patients and Wards.

\section{Pathogenesis of Infectious Disease}

By Cedric A. Mims. Pp. $x+246$, illustrated, hard cover. Academic Press Inc., London, 1976. £6.80, \$14.75.

Professor Mims has written a very timely and interesting account of the relationship between microorganism and host. The remarkable upsurge of research on the fundamental properties of microorganisms and the corresponding expansion in the field of immunology have combined to unravel some of the mysteries of infectious disease but in doing so have revealed the complexities of the problems still to be solved.

Professor Mims must be commended for collating this vast amount of information in a most readable and stimulat ing book. Unfortunately his efforts have been slightly marred by an excessive number of typographical errors and a few statements of fact which may be disputed. Are Koplik's spots really small ulcers in the mouth? Is whooping cough a systemic infection and does the organism persist in the nasopharynx for many months? Surely not. Moreover alumprecipitated diphtheria toxoid and not pertussis vaccine was shown to be mainly responsible for provoking paralysis in poliomyelitis. It is confusing to list Trypanosoma brucei without qualification as the cause of sleeping sickness in man and misleading to state that latent Plasmodium vivax can cause an attack of malaria many years after returning from the tropics. While I would accept Professor Mims' opinion that 'there are superb opportunities for mucosal spread during venery' it is no longer accurate to state that 'microorganisms rarely occur in semen'. In man, semen has been shown to harbour cytomegalovirus, Herpesvirus hominis type II and hepatitis B antigen; in cattle, Brucella abortus; in horses and mules, Trypanosoma equiperdum. In the table listing the pandemic strains of influenza virus the 1918-19 strain has been designated Ao. Since influenza virus was first isolated in 1953 it would, perhaps, be more accurate to restrict this designation to influenza $A$ viruses circulating between 1933 and 1946. Despite some minor criticisms I can thoroughly recommend this monograph to anyone interest in this fascinating subject.

There is a useful addendum summarizing current knowledge on vaccines and a helpful glossary defining some of the terms used in the text. The index is comprehensive.

\section{Pathology of Peripheral Nerves}

By R. O. Weller and J. Cervós-Navarro. Pp. vii $+22 \overline{\overline{\bar{\alpha}}}$. illustrated, hard cover. The Butterworth Group, Londored The most important aspects of the pathology of periphera nerves have been covered comprehensively in this 225-page volume. The modern approach is emphasized by attention to modern concepts, methods, and recent developments, backed by experience in both experimental and diagnostic pathology, while evaluating methods critically.

The book offers an historical review, techniques of biops and histological preparation, descriptions of normal am pathological peripheral nerves, and of peripheral net diseases. The last chapter deals with tumours of the peivi pheral nervous system. In the appendix there is a guide to the examination of peripheral nerve biopsies, a summary of $t$ pathology and a synopsis of the major groups of peripheral neuropathies.

This volume will be invaluable as a compact source $\overrightarrow{g f}$ reference. It provides, for pathologists, techniques of fixation and handling of biopsy specimens ensuring proper orientatiōn and optimum quality. Epoxy resin embedding is favoured for biopsy material and perfused animal tissue. Histochemicict techniques are documented briefly and competently. The clinical features of peripheral nerve disease are examined act classified; electrophysiological techniques and their inte pretation are discussed.

The subject matter is presented with clarity of definitions are clear and facts are well delineated. The supo cinct writing makes the subject interesting and the assimilable. Typographical detail, photographs and diagraios are good. The book is recommended for pathologists, pos graduate students, neurologists and those in related disci lines for whom it will be of great value as a practical guideon

\section{Pathology of Tumours of the Nervous System}

By Dorothy S. Russell and Lucien J. Rubinstein. PA 448, illustrated, hard cover. Edward Arnold, London, $197 \mathrm{~B}$. £25.00.

The third edition was published in 1971 having 429 pages and 339 illustrations. This new edition has 448 pages and 331 illustrations. Aspects of tissue culture are now incofporated, in shortened form, in the relevant parts of the book rather than being in one chapter, by the late Charles Lumßden, at the end of the book. Of some fifty new illustrations about half are electron micrographs. The text has begi thoroughly revised, in the light of the authors' experience and of published work, in particular in relation to the experimental production of tumours of the nervous systefl with alkylating agents and oncogenic viruses, to the involvsment of the CNS in leukaemia and lymphoma and to the endocrinological aspects of pituitary adenomas. The sectio on medulloepithelioma, cerebral medulloblastoma and the tumours of the pineal parenchyma are improved, as the result of increased experience of these rare tumours. TH nosological status of the angioblastic meningioma and $\mathrm{ht}$ relationship to the haemangiopericytoma are fully discussed. The further contributions made by electron microscopy to understanding of the cellular composition in particular of the capillary haemangioblastoma, the ependymoma, t medulloblastoma, the ganglioglioma and the retinoblastonfa are noted. This edition continues to be written for practising pathologists, postgraduate students, neurologists and neuresurgeons. Those who were brought up on the old editiogs will find much that is new in the fourth. Those to whom to 